\title{
ROBERT ANDREW GOULD
}

(1960-2002)

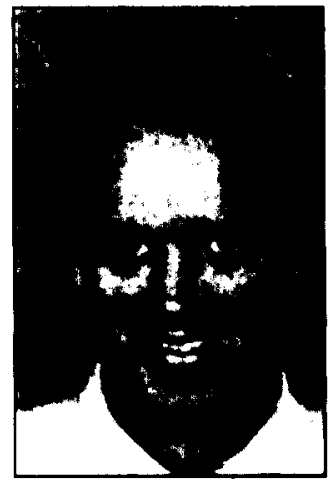

Debo confesar que la muerte del profesor norteamericano Robert Andrew Gould, ocurrida el pasado 26 de agosto, me produjo una fuerte e indescriptible conmoción. Los psicólogos estamos hartos de hablar sobre estrategias de afrontamiento $\mathrm{y}$ otros procedimientos para hacer frente al estrés, pero un suceso vital puede resultar extremadamente dañino si éste es traumático, inesperado e incontrolable. Y estas tres características del suceso de algún modo me han venido marcando desde que conocí la triste noticia. El Dr. Gould era psicólogo y profesor de psicología en la universidad más prestigiosa de Estados Unidos, la Harvard University (Massachusetts General Hospital y Harvard Medical School), en Boston (Massachusetts). Trabajaba desde hacía 8 años como profesor e investigador en esta universidad; su muerte, a la edad de tan sólo 42 años, nos sobrecogió a todos sorpresivamente.

El profesor Gould había nacido en North Brookfield, y realizó sus estudios primarios en St. Andrews School en Boca Ratón (Florida). Se graduó en el Davidson College en 1982, y obtuvo el grado de doctor en psicología en 1993 en el Virgi- nia Polytechnic Institute. En 1991 se había casado con Bonnie MacDonald, viviendo desde entonces en Marblehead (Massachusetts), la ciudad de su esposa, con ésta y sus dos hijas Olivia (8 años) y Louisa (4 años).

Hace poco más de 5 años, en abril de 1997, tuve la oportunidad de conocer personalmente al Dr. Gould cuando éste asistió como conferenciante invitado al I Congreso de la Asociación Española de Psicología Clínica y Psicopatología, celebrado en Madrid, para hablar sobre el tratamiento del trastorno de pánico según los recientes métodos de autoayuda. De hecho, el Dr. Gould, a pesar de su juventud, era ya por entonces muy conocido internacionalmente por sus aportaciones al tratamiento del trastorno de pánico basado en la autoayuda. Algunos de sus primeros trabajos, muchos de ellos publicados en colaboración con George A. Clum, hoy auténticos clásicos de la materia, tales como "The use of bibliotherapy in the treatment of panic: A preliminary investigation" (Behavior Therapy, 24, 241-252, 1993) o "Self-help plus minimal therapist contact in the treatment of panic disorder: A replication and extensión" (Behavior Therapy, 26, 533-546, 1995), fueron en su momento pioneros sobre los métodos de autoayuda aplicados al tratamiento del pánico, lo que le convirtieron en una de las personalidades más sobresalientes a nivel internacional en el campo del trastorno de pánico.

Sin embargo, aún siendo el trastorno de pánico su principal área de estudio, el Dr. Gould muy pronto destacó también por sus contribuciones al estudio de otros trastornos de ansiedad, tales como la 
fobia social y el trastorno de ansiedad generalizada. En los últimos años había adquirido una gran reputación internacional por sus aportaciones sobre la evaluación de los tratamientos de los trastornos de ansiedad. Entre las contribuciones del profesor Gould, en este sentido, no sólo se encuentran sus conocidos metaanálisis, los cuales constituyen un punto de referencia obligado para los interesados por el tratamiento de los trastornos de ansiedad, sino también sus estudios comparativos sobre la eficacia terapéutica del tratamiento cognitivo-conductual y las terapias farmacológicas (benzodiacepinas, inhibidores selectivos de la recaptación de serotonina, etc.). Su reputación desbordaba las ya de por sí amplias fronteras de los Estados Unidos de América. Por ejemplo, por no ir más lejos, algunos profesores de universidades españolas, atraídos por su inspiración y jovialidad, habían asistido como profesores visitantes a sus enseñanzas en la Behavior Therapy Unit, en Boston, para formarse en terapia de los trastornos de ansiedad. Es innegable que el Dr. Gould era uno de los jóvenes investigadores de mayor proyección en el campo de los trastornos de ansiedad.

No puedo dejar de enfatizar, sin duda porque me afecta personalmente, lo importante que resultaba su participación anual en nuestros cursos de postgrado de Psicopatología y Salud de la Universidad Nacional de Educación a Distancia. Su asistencia como profesor de los trastornos de ansiedad, ritualmente durante varios días del mes de mayo, transmitía a dichos cursos el aire fresco e innovador, la calidad y actualización que sólo él, un entusiasta y joven investigador y profesor, de allende los mares, podría brindarnos.

El profesor Gould, además de disfrutar de su trabajo relacionado con la investigación y la docencia universitaria, gustaba practicar muchos hobbies con su familia y amigos en su tiempo libre. No en vano era un gran aficionado a diversos deportes, que efectuaba de forma bastante habitual, como el tenis, el windsurfing, el camping, o el mountain biking. Era una persona atlética, jovial, simpática, afectiva, alegre, comunicativa, amable... Practicaba deporte con asiduidad. Murió repentinamente mientras jugaba un partido de tenis por un ataque al corazón; tal vez a causa de alguna cardiopatía desconocida que los médicos nunca fueron capaces de detectar. Era casi perfecto; su único pecado fue morir demasiado joven. La Psicología ha perdido un gran investigador y profesor. Nosotros hemos perdido algo más, hemos perdido también un amigo y compañero muy especial. Echaremos de menos sus contribuciones e innovaciones en nuestra psicología, sus conferencias y su amistad, pero, sobre todo, le echaremos de menos todos los años, durante esos días del mes de mayo...

\author{
Bonifacio Sandin \\ Universidad Nacional \\ de Educación a Distancia
}

